\title{
Public acceptance and perceptions of alternative water sources: A comparative study in nine locations
}

\author{
Anna Hurlimann ${ }^{1 *}$ and Sara Dolnicar ${ }^{2}$ \\ ${ }^{1}$ Faculty of Architecture Building and Planning, The University of Melbourne, Melbourne, Australia 3010; \\ hurac@unimelb.edu.au; +61 383446976 \\ ${ }^{2}$ UQ Business School, The University of Queensland, Brisbane, Australia 4072 \\ * Corresponding Author
}

To cite this article:

Anna Hurlimann \& Sara Dolnicar (2016) Public acceptance and perceptions of alternative water sources: a comparative study in nine locations, International Journal of Water Resources Development, 32:4, 650-

673, DOI: $\underline{10.1080 / 07900627.2016 .1143350}$

\begin{abstract}
Public acceptance of recycled water, desalinated water and rainwater is compared across nine international locations: Australia, Belgium, Canada, Israel, Japan, Jordan, Mexico, Norway, United States of America (specifically in Los Angeles). An on-line study was conducted in 2012, with 200 participants recruited to be representative of their respective location (1800 in total). The study investigated participants' intended use of and perceptions of alternative water sources. Results indicate that respondents clearly discriminate between alternative water sources. Water source preference varied between water use purpose. Significant differences were found in the percentage of respondents willing to use alternative water sources between locations. Additionally the study found that there were significant differences in perceptions held of five water sources across locations.
\end{abstract}

Key words: alternative water sources; international; recycled water; desalinated water; rainwater tanks; public opinion; bottled water;

\section{Introduction}

An ample supply of clean water is critical to sustain human life and the environments on which humans and nature depend. Humans have altered natural water regimes over time with the aim of securing an adequate supply of water to meet the needs and demands of population settlements (Mumford 1989). For over a century, infrastructure intensive, centralised water supply systems have dominated the provision of water in cities of developed nations. Yet, in many developing nations, the provision of water supply is not wide spread, and when it does exist, is often unreliable in terms of quality and continuity of supply (World Water Assessment Programme 2009). To address quality concerns, consumers in such situations often diversify the sources of water they access and employ some type of water treatment - such as boiling water - to improve quality (Rosa and Clasen 2010).

The sustainability of the centralised, supply-side approach to urban water supply management is being challenged in many locations due to the increasing pressure placed on these systems by changes in population, land use, environment, and climate. Because of the limitations of traditional centralised supply systems, new approaches to water management have been called for. These include the introduction of the concept of 'integrated water resources management' (Biswas 2008) and augmentation of existing water supplies with non-traditional sources such as recycled wastewater and desalinated seawater. 
There are numerous examples of the successful implementation of water augmentation projects, including many desalination plants, for example, the city of Perth in Australia where $41 \%$ of water is sourced from desalination (Water Corporation 2015). Successful potable recycled water projects include but are not limited to Singapore (Leong 2015) and Namibia (du Pisani 2005). However, the proposed solutions to current water supply challenges are not without hurdle. The implementation of alternative water sources for potable purposes has faced barriers in some instances, for reasons including poor political support and public acceptance (see for example, the case of a proposed desalination plant in Sydney Australia: Davies 2006; and the proposed use of recycled water for potable purposes in Toowoomba Australia: Hurlimann and Dolnicar 2010). Further knowledge about the factors that contribute to the successful introduction of alternative water sources will provide critical information to meet future water needs under changing conditions.

Knowledge surrounding the factors contributing to the acceptance of alternative water sources is growing, thanks to an increasing body of research. While there is a substantial collection of research into recycled water acceptance, less detailed knowledge exists for other alternative water sources such as desalinated seawater, stormwater, and rainwater. Additionally attitudes across alternative water sources or locations have rarely been compared and no large cross-nation study of public acceptance of alternative water sources published to date. Such research would provide insights into the similarities or differences across divergent water, cultural and social contexts. The key proposition of this paper is that these differences in local water, political, environmental and cultural situations will be associated with differences in perceptions and acceptance of water from alternative sources. Hence the research questions which this paper addresses are:

- Are there significant differences in stated willingness to use recycled water, desalinated sea water, and rainwater, between people in locations characterised by different water circumstances?

- Do perceptions of recycled water, desalinated sea water, rainwater, bottled water and current tap water, vary between people in locations characterised by different water circumstances?

This knowledge gap was addressed through a study in 2012 which simultaneously conducted surveys with 200 people in each of nine locations (1800 participants in total) from nine countries. Public willingness to use and perceptions of alternative water sources were compared across the nine locations. The paper begins with an overview of previous research relating to willingness to use and perceptions of alternative water sources, before detailing the research method employed, and providing information about the locations of study. The results are then presented and discussed, and conclusions drawn.

\section{Previous studies on acceptance of alternative water sources}

Research into community acceptance of water alternatives has been conducted across a wide range of locations, including Europe (Aitken et al. 2014; Jeffrey and Jefferson 2003) and the Middle East (AlMashaqbeh et al. 2012; Alhumoud and Madzikanda 2010; Carr et al. 2011). A significant body of research developed in the USA since the 1970s focusing on recycled water acceptance (e.g. Bruvold 1972; Bruvold 1988; Bruvold 1992; Bruvold and Ward 1970; Haddad et al. 2009; Macpherson et al. 2013; Ormerod and Scott 2013; Resource Trends Inc. 2004). Similarly, a long history of research into public acceptance of recycled water use is also evident in Australia (e.g. Fielding and Roiko 2014; Hurlimann 2008; Marks 2004; Sydney Water 1996). Despite this extensive research, knowledge gaps do exist, hampering a thorough understanding of the conditions which facilitate public acceptance of a range of alternative water sources and how acceptance can be influenced 
across locations. An overview of prior research in this field, and the gaps which exist is provided below.

\section{Understanding public acceptance of alternative water sources}

Much work is dedicated to the study of public perceptions of recycled water, the most extensively researched alternative water source. Most of this work was hypothetical in nature; the survey participants had never actually experienced recycled water. A key finding that emerged form this body of work is that public acceptance of recycled water is higher when the water does not come in direct contact with the body. For example, the use of recycled water for irrigating gardens is more acceptable than it is for drinking (e.g. Alhumoud and Madzikanda 2010; Browning-Aiken et al. 2011; Bruvold 1988; Marks et al. 2006; McKay and Hurlimann 2003; Sydney Water 1996). The specific uses of recycled water which have been investigated have varied from study to study, as has the number of uses investigated, yet this overall acceptance trend prevails. It is important to note that the exact proportion of the public found to support the use of recycled water varies between studies and across time periods.

Hurlimann's (2008) study of willingness to accept recycled water, at four periods of time between $2002-2007$ shows that attitudes were not stable over the study period. The author believes that the differences in attitudes observed over these time periods could be explained by factors relating to the introduction of the non-potable source water for the recycled water system into the suburb - Mawson Lakes in South Australia. Similarly Price et al.'s (2010) long term study with residents of South East Queensland conducted from November 2007 - December 2008 found that support for indirect potable reuse changed over time (decreasing significantly across two of the four time periods $p<0.01$ between the first two and last two time periods). The highest level of support $(73.9 \%)$ was found during the baseline study. Support was at its lowest in the final survey period $(70.2 \%)$. As Price et al. discuss, the surveys were conducted at a critical time for the region of South East Queensland in terms of water supply. A potable reuse scheme was being planned and constructed. During the first survey the region's dams were at $20 \%$ of capacity. By December 2008 the dams were back to $40 \%$ of capacity, and the government announced that the dams would not be augmented with recycled water unless their capacity had decreased to a critical point. Price et al's additional findings indicate that many respondents would prefer not to drink potable recycled water and that their willingness to do so would decrease if other alternatives were available, including further rainfall (Price et al. 2010).

In comparison, acceptance of desalinated water is not as extensively investigated. Recently, Theodori et al. (2011) surveyed 1228 state of Texas residents by mail in 2008 to gauge perceptions of whether desalinated water could be safely used for a range of purposes. They found acceptance pattern similar to those of recycled water. More recent research in Perth (Australia) has compared public attitudes to using desalinated water for the city's supply (Gibson et al. 2015). The authors found that acceptance of desalination remained constant over the two survey periods $(2007-74 \%$ support; $2012-73 \%$ support). Psychological variables were found the most dominant factors driving acceptance, including: perceived outcomes, fairness, and low perception that the system may fail.

Recent studies have investigated attitudes towards the use of rainwater. A number of studies have focused on factors facilitating increased use (e.g. Barthwal et al.2014; Domènech and Saurí 2011; Gabe et al. 2012). Dobrowksy et al. (2014) conducted 68 interviews with residents of the Kleinmond development in South Africa. All houses in the development have a rainwater tank, but at the time of interview did not have a municipal (centralised) water supply. The interviews addressed respondent use of rainwater, and found that $92 \%$ of respondents use the rainwater for laundry, $70 \%$ 
for cleaning, 46\% for gardening, 44\% for bathing, 24\% for drinking and 19\% for cooking. Of the $24 \%$ who indicate they use it for drinking, the majority indicated they only do so sometimes. The study did not investigate the principle source of water used for drinking, or whether the participants boil water for drinking.

Similarly, in the Mekong Delta region of Vietnam, Özdemir et al. (2011) surveyed 619 households to understand current practices and preferences regarding rainwater harvesting and other water sources. The study found that rainwater was the most frequently stated use of water across both the wet and dry seasons ( $85 \%$ wet season and $84 \%$ dry season). While only $78 \%$ of respondents indicate they use rainwater for cooking, the use of well water was $9 \%$ for drinking, and $17 \%$ for cooking. These findings point to people discriminating clearly between water sources and displaying different preferences.

\section{Attitudinal differences between alternative water sources}

A small number of studies have compared public attitudes to different alternative water sources. Dolnicar and Schafer's (2009) Australian study compares stated preferences for recycled water and desalinated water across twenty water use purposes. Desalinated water was found to be the preferred water source for close-to body uses such as drinking and cooking. Recycled water was preferred for less personal uses such as watering the garden and flushing the toilet. Dolnicar and Hurlimann's (2010) later study, also conducted in Australia, found an overall stated preference for desalinated water over recycled water. Recycled water was only preferred for watering the garden. In a repeat cross sectional study in Australia, Dolnicar et al. (2014) asked respondents about their preferred drinking water source in January and July 2010. Ordered preference remained constant with tap water the preferred source $(45 \%, 44 \%)$, followed by bottled water $(28 \%, 27 \%)$, rainwater from their own tank $(24 \%, 26 \%)$, desalinated water $(1 \%, 3 \%)$, then recycled water $(1 \%, 1 \%)$.

A research study conducted for the WateReuse Research Foundation in the USA (Macpherson and Snyder 2013) sought to investigate the impact of information on acceptance. Specifically, it was investigated whether presenting recycled water use in the context of the urban water cycle, and the fact that all water is recycled, would increase acceptance of recycled water. The research investigated perceptions of four water supply options: current practice (treated wastewater is discharged into rivers and becomes drinking water for downstream communities), blended reservoir, upstream discharge (treated wastewater is discharged into the river upstream from the community) and direct potable reuse. The authors found that 'blended reservoir' was preferred, followed by 'upstream discharge', 'direct potable' and 'current practice'.

More recently, Fielding et al. (2015) compared Australians' comfort with drinking four alternative water sources across four studies. They found that comfort with drinking rainwater was highest, and recycled water lowest, with desalinated water and stormwater in between. They did not provide participants with a definition of each water source. Factors found to be significant positive predictors of comfort with drinking the alternative water sources investigated included participants' trust in science and the government, and their comfort with technology in general. Leonard et al. (2015) compared community attitudes to three alternative water supply systems using stormwater through managed aquifer recharge. These were: a third pipe (non-potable) system; an indirect potable system where the water is recovered from the aquifer and transported to the drinking water reservoir and treated with the existing water supply; and direct potable use where the stormwater is recovered from the aquifer to a local treatment plant then distributed in the drinking water mains. In total, 1043 respondents representative of the greater Adelaide population were surveyed. The results indicated that $73 \%$ supported the non-potable use, $57 \%$ the indirect potable use, and $55 \%$ the direct potable use. 
Overall, there have been a limited number of studies which have compared public attitudes to more than one alternative water source at the one time period. Furthering this work would be beneficial.

\section{Perceptions of alternative water sources}

There is a small but growing body of literature exploring public perceptions of the attributes (e.g. aesthetics, and health and safety) of different water sources, including tap water (Bruvold 1968; Doria 2010; Hurd 1993) and recycled water (Hurlimann and McKay 2007). More recently, studies in Australia have compared public perceptions of multiple sources of water and found significant differences between sources (Dolnicar et al. 2014; Dolnicar and Schäfer 2009). For example, Dolnicar et al. 2014 investigated Australian perceptions of five water sources: bottled water, current tap water, rainwater from a tank, desalinated water and recycled wastewater. They found a significant difference in the evaluations respondents made between each water source for a wide range of desirable and undesirable water attributes. Dolnicar et al. (2014) found that bottled water and tap water were perceived as healthy and safe for human consumption. Recycled water was perceived by respondents as the most poorly performing source of water in terms of aesthetic attributes and health concerns. To our knowledge there has not been a study to assess public perceptions of a range of water sources and compare these across multiple locations.

\section{Location differences in public acceptance}

Only a limited number of studies have compared public acceptance of alternative water sources across locations. Roseth (2008) compared attitudes towards recycled water across purposes in five Australian locations (Adelaide, Brisbane, Melbourne, Perth and Sydney). Brisbane respondents were more willing to use recycled water for a range of purposes. Respondents from Adelaide were less willing to accept the use of recycled water in the cooking industry, for household pools, for cooking and drinking. The Macpherson and Snyder (2013) study discussed earlier also involved the quantitative comparison of attitudes to the alternative water supply options across two survey samples - one in the USA and the other in Australia. They found that there were differences in preferred water source between respondents from those two locations. The report indicates that the majority of respondents in both countries were "willing to" drink, or "generally ok" with each of the four scenarios presented. However more Australians were "willing to" drink the water from each scenario. However no information was provided about whether the difference was significant or not.

Our study contributes to this body of work by comparing three alternative water sources for seven purposes across nine locations, in nine countries.

\section{Method}

An international online survey was conducted in June 2012 in nine countries: Australia, Belgium, Canada, Israel, Japan, Jordan, Mexico, Norway, and the USA (specifically Los Angeles, California). The purpose was to explore how acceptance and perceptions of recycled water, desalinated sea water and rainwater varied between these nine diverse locations, and their associated diverse water, cultural, and social contexts.

\section{Locations}

The locations were chosen to be diverse with respect to water scarcity, water supply, political system, general societal environmental approach and outlook, and climatic and socio-economic 
factors. Values for each location included in the sample are presented in Table 1 - data at the national level. It should be noted that these indicators were used as a guide only, given that some of the sources used to compile Table 1 are dated. For example, the FAO (2013) figures regarding water supply source for each location are from the early 2000s; desalinated and recycled water production capacity has increased in many countries since then.

Long term average annual precipitation was taken from the 'Aquastat' online database of the Food and Agriculture Organisation of the United Nations (FAO 2013).

Total water withdrawn was taken from the Aquastat online database (FAO 2013).

Pressure on water resources was taken from the Aquastat online database (FAO 2013). The database calculates pressure on water resources by establishing the total freshwater withdrawn by each nation, and expressing it as a percentage of the nation's annual renewable water resources.

Water supply. Given the limitations on the 'pressure on water resources' measure above, we also considered broader water supply conditions of the locations including historical water supply shortfalls and water supply source to ensure a diversity of water supply conditions in the sample (see 'water supply' column in Table 1). An additional column details the water supply source for each column, accessed from the Aquastat online database (FAO, 2013).

Population density was taken from the Aquastat online database (FAO 2013) and is measured in inhabitants per $\mathrm{km}^{2}$.

Political system was drawn from the Freedom House (2011) 'Freedom in the World' index which is based on two measures: 'political rights' and 'civil liberties.' Each is measured on a scale ranging from 1 (most free) to 7 (least free). Countries are then grouped into three categories: free (values below two on each measure), partially free (values of three, four or five on each measure), and not free (values of more than six, or mixed scores of one five and one six/seven).

General societal environmental approach and outlook was measured with the 'social and institutional capacity' component from the ESI 2005 (Yale Center for Environmental Law and Policy et al. 2005). It comprises four indicators: 'science and technology,' 'environmental governance,' 'eco-efficiency,' and 'private sector responsiveness,' each containing 2-12 variables. The 146 countries included in the ESI are then ranked 1-146 (where $1=$ highest ranking, and $146=$ lowest ranking).

Average daily minimum and maximum temperature was sourced from the 2006-2008 OECD Data compendium (OECD 2008).

Life expectancy at birth was gathered from the World Bank Development Indicators (The World Bank 2012), using the most recent data available at the time of publication (2010).

Income indicators were gathered from the World Bank Development Indicators (The World Bank 2012 p.23) using the measure of "purchasing power parity (PPP) gross national income (GNI) per capita". For this measure, the data is converted to international dollars using PPP rates, and divided across the population (calculated mid-year).

Study locations were selected in a way to ensure a diverse range of water-related conditions were represented. Also, the online fieldwork company had to be able to provide a sufficiently large representative sample for each of the countries ultimately included.

$<$ Insert Table 1>

\section{Participant recruitment}


A research-only, permission-based internet panel recruited 200 participants in each of the nine locations. The sample size per location was relative small because we were forced to find a good compromise between cost and margin of error. It was determined that a seven percent margin of error for the worst case scenario of a 50\% estimated population proportion was acceptable (Cochran, 1977). Data was collected in June and July 2012. The Melbourne office of an international marketing research consultancy, engaged partners they had in the additional eight locations. The consultancy were instructed to recruit a nationally representative sample (age, gender, location), except for LA - where this was to be representative for LA. They were asked to draw a sample of respondents from neighbourhood/ regional socio-economic quotas in each location.

The survey was made available in the official language of each location, with professional translators used to translate the survey from its original English version. The survey took approximately thirty minutes to complete. Respondents were paid a small compensation fee for their efforts.

\section{Survey}

Respondents were asked a series of questions about their attitudes to, perceptions of, and behaviours relating to water. They were asked additional questions about their general environmental attitudes and behaviours, living conditions, and socio-economic information. In designing the survey, the researchers were mindful to use concepts that could be understood across nations. For this reason, early in the survey, respondents were provided with a short statement of information about various water sources discussed in the survey - to ensure a common understanding across respondents. This information can be found in Box 1. Information provided also sought to connect the water sources with locations already using that source to ground the scenario in a real-world example. This was done to address one limitation of this study, its hypothetical nature.

\section{$<$ Insert Box 1>}

The survey investigated stated willingness to use three alternative water sources: recycled water, desalinated water, and rainwater, for seven purposes. Respondents were asked:

"For the following question, imagine that you live in a town that is facing a water shortage. Please indicate whether or not you would use <water source> for the following purposes."

Respondents were presented with a list of seven water use purposes (watering plants, washing clothes, washing my body, drinking, toilet flushing, cooking, cleaning) for each water source. Response options were yes or no. Binary options were offered deliberately given the cross-cultural nature of the study. It is well known that respondents from different cultural background use response options differently. These differences in so-called response styles (Paulhus 1991) manifest in the data set as biases which can lead to misinterpretation of findings. Binary answer options eliminate the possibility of most biases occurring (Rossiter et al. 2015).

Respondents were also asked about their perception of five water sources (purified wastewater, purified seawater, tap water, bottled water, rainwater), using the following question:

"You will now see a list of descriptions of water. For each kind of water, please indicate whether or not they apply. If you are not sure, please tick the option you think is more likely."

Respondents were then presented with a list of nine perception statements (presented in random order for each respondent, except for the 'knowledge' question, which was fixed at last). The perception statements were originally used by Dolnicar et al. (2014) in an Australian study, and 
related to aesthetic perceptions, cost, environmental impact, convenience and knowledge. The response options were yes or no.

Respondents were also asked what water source they use for drinking. They were presented with six water sources: town supplied water, rainwater tank, bottled water, ground water, recycled water and desalinated water, in addition to the options: 'I boil my water', 'other', and 'don't know.' Multiple responses were allowed, except for when 'don't know' was chosen. Boiling water was included in this research because it represents a common practice to improve water quality (Katuwal and Bohara 2011; Sodha et al. 2011). Additionally, it is common practice for boil water alerts to be issued when centralised water supply quality has been compromised (Hrudey and Hrudey 2006).

\section{Results and discussion}

\section{Sources of drinking water currently utilised}

Sources of water used by respondents for drinking are shown in Table 2. Dark grey shading indicates which water source is used by the largest percentage of respondents in each location for drinking; midgrey indicates the second largest source of drinking water, and light grey the third largest source of drinking water. The results indicate that 'town supplied water' was the dominant source of drinking water for respondents in six of the countries surveyed. Bottled water was most frequently the main drinking water source in Jordan, Belgium, and Los Angeles. Only a few respondents indicated they drink recycled or desalinated water. The source of their current centralised water source was not captured in the survey.

\section{$<$ Insert Table 2>}

Jordan had the most diverse drinking water sources stated by respondents. In addition to bottled water (67\%), 30\% of Jordanian respondents indicated they drank town supplied water, 19\% drink water from a self-supplied rainwater tank, $17 \%$ recycled water, and $11 \%$ ground water. This diversity of water sources used by respondents may be due to the unreliability of town supplied water, and gaps in supply reported by Abdulla and Al-Shareel (2009). The diversification of drinking water supplies is in line with that employed by respondents in Özdemir et al.'s (2011) study in the Mekong Delta. Additionally, Jordan had the highest percentage of respondents who reported boiling drinking water (14\%) behind Australia and Japan (10\% each), which again may be reflective of the real or perceived issues surrounding water quality in many locations in the country, as boiling water (and doing so properly with proper storage) is an important public health measure (Rosa and Clasen 2010). While town supplied water was the main source of drinking water indicated by the respondents from Mexico, 37\% also drank bottled water, 23\% ground water, and 13\% rainwater from their own tank. Similar to Jordan, this may be due to lower reliability of centralised supply in Mexico compared to other countries. As indicated in Table 1, full access to "improved water sources" for Mexico and Jordan's populations has not yet been reached.

In Australia $75 \%$ of respondents indicated they drank town supplied water, the second highest percentage behind Norway ( $85 \%$ ). However $27 \%$ of Australians indicated they drink bottled water, and $10 \%$ rainwater. A previous Australian study found that $42 \%$ of people in South Australia drink rainwater due to concerns about aesthetic and chemical properties of tap water (Heyworth et al. 1998). Norway had the lowest number of respondents indicating they drink bottled water (19\%), while $8 \%$ indicated they drink ground water. 
Overall the results indicate that a diversity of water sources is drawn upon for drinking in each of the countries surveyed, with tap water and bottled water the dominant sources overall. These results may be reflective of the rise in bottled water sales globally over the past two decades (Parag and Roberts 2009). This study did not assess frequency of use of the stated drinking water sources, so the conclusions drawn here are limited in this regard. This means it is not known whether the $27 \%$ of Australian respondents seldom or regularly drink bottled water.

\section{Intended use of alternative water sources}

Intended use of recycled water, desalinated water and rainwater from a tank were firstly analysed at the whole sample level, then differences between locations were explored. The percentage of respondents (whole sample) who indicated they would use each alternative water source for the seven purposes is shown in Figure 1.

\section{$<$ Insert Figure 1>}

As shown in Figure 1, the overall percentage of respondents who indicate they intend to use recycled water and rainwater increases with decreasing physical contact with the water. For recycled water, this is in line with findings from previous research (e.g. Alhumoud and Madzikanda 2010; BrowningAiken et al. 2011; Bruvold 1988; Marks et al. 2006; McKay and Hurlimann 2003; Sydney Water 1996). Overall this trend holds for desalinated water, but it receives a lower preference for watering the garden than for toilet flushing and cleaning. Similarly toilet flushing receives the same rating as cleaning. Statistical tests (chi square) were undertaken to establish whether there was a significant difference between water source for each water use purpose. All were found to be significant.

Figure 1 illustrates that for the purposes of water use which are have close to person applications (drinking, cooking, washing body, washing clothes), desalinated water had the highest percentage of respondents who indicate they intend to use the source, followed by rainwater, then recycled water. For cleaning, rainwater has the highest percentage of respondents who indicate they intend to use the source, followed by desalinated then recycled water. However, for toilet flushing and garden watering, rainwater received a higher intended use, followed by recycled water, then desalinated water. This study places the stated preference for the use of rainwater for a range of water use purposes alongside desalinated and recycled water. The results reported here are largely in line with previous research comparing preferences for recycled and desalinated water, and that for garden watering (Dolnicar and Hurlimann 2010) and toilet flushing, recycled water is the preferred source (Dolnicar and Hurlimann 2010; Dolnicar and Schäfer 2009).

Table 3 presents results by location. The table uses shading to indicate which water source (recycled, desalinated and rainwater) is most accepted (dark grey), second most accepted (mid-grey) and third most accepted (light-grey) for each location. The chi-square test was used to establish whether or not the observed differences across locations is not random, for each water source / use application. Given the large number of independent test being run (nine locations by seven water sources $=63$ ), there is a chance that the significance of each item is over estimated. Thus, in order to account for this, the p-values were Bonferroni-corrected to account for multiple testing. The results indicated that the observed differences for each water source/use tested were not random, significant at the 0.01 level, except for three uses: desalinated water for body washing, rainwater for cleaning, rainwater for watering plants. 


\section{Water perceptions across five water sources}

The results presented in Table 4, show by location, the percentage of respondents who agreed with each perception statement, for the five water sources included in this question. The chi-square test (Bonferroni corrected) was used to establish whether or not the observed differences across locations is not random for each water source / perception statement. The results indicate that the observed differences for each water source / perception statement tested were not random, significant at the 0.01 or 0.05 level, except for 'is expensive' for 'rainwater from a tank' which was not found to be significant.

\section{$<$ Insert Table 4>}

While there were differences in the percentage of respondents who agreed with each statement between locations, there were some similarities in terms of water source perception order. For example, in comparison to the other water sources in the survey, bottled water was perceived to be the cleanest water source, by the highest proportion of respondents in each location. Bottled water was also perceived as the least harmful to people's health of all water sources in all locations except for Norway, where it was perceived as the second lest harmful overall. Bottled water was perceived to be the most expensive source of water in all locations, and the least environmentally friendly in all locations but Mexico and Jordan.

Additionally, rainwater was perceived to be the least expensive source of water in all locations. Additionally it was perceived as the most environmentally responsible source of water in all but two locations (Norway and Mexico), and the least clean source of water in all but two locations - Israel and Jordan. In terms of 'current water supply', this source was rated the most convenient source of water in all but three locations - Mexico, Japan and Jordan. For recycled water and desalinated water, respondents had the lowest stated knowledge of these water sources, and they were seen as the least convenient sources of water. While the percentage of respondents agreeing with each perception statement differed between locations, the average agreement scores across locations indicates that recycled water was perceived by the highest proportion of respondents as potentially the most harmful to human health, and the second least clean source of water - behind rainwater from a tank.

In order to explore whether there is a correlation between perceptions of the water sources and willingness to use them, Pearson Correlation analysis was undertaken. Given the large number of perception statements investigated in this study, and the number of alternative water sources, the analysis was undertaken separately for each kind of water for one water use (drinking) and one perception statement: "<alternative water source $>$ is potentially harmful to human health." The analysis was undertaken for the overall sample. The perception statement for each water source was tested against the willingness to use statement for drinking purposes for the corresponding water source. A significant $(p=0.01)$ and negative correlation was found between the perception that the alternative water source was potentially harmful to human health, and willingness to use it for drinking purposes (recycled water $r(1791)=-0.169$; desalinated water $r(1791)=-0.21$; rainwater $r(1791)=-0.279)$. Indicating a role for water authorities to improve communication about potential risks to human health associated with various water sources, to allay community concerns. Further research to explore this would be beneficial. 


\section{Discussion of stated water preferences and perceptions in specific locations}

Australia: The water source Australians preferred most for each use varied depending on purpose (Table 3). Desalinated water was preferred for drinking and cooking. In comparison to other locations, Australians were most willing to use desalinated water for cooking. This may be due to the fact that desalinated water was seen by Australian respondents to be the cleanest, and least harmful to human health behind bottled water. They were the location most willing to use recycled water on the garden, and the most willing to drink and cook with rainwater, perhaps reflective of a cultural history of drinking from rainwater tanks (Heyworth et al. 1998), and a high penetration of rainwater tanks in some contexts (e.g. 41\% in Victoria, Hurlimann 2011). Additionally, results in Table 4 indicate Australians perceive rainwater to be the most environmentally friendly source of water, and it is the water source for which they state they have the highest level of knowledge.

Belgium: Belgian participants preferred to use desalinated water for the four most personal uses investigated, and rainwater for the three least personal (Table 3) with the latter also the water source which the largest percentage of respondents perceived as environmentally friendly. In comparison to other locations, Belgian study participants were least willing to use desalinated water for drinking purposes and most willing to use rainwater for toilet flushing. This may be explained by the fact that they were the location which had the largest percentage of respondents perceive that rainwater from a tank is convenient to use.

Canada: Canadians preferred the use of desalinated water for all purposes except for washing clothes and toilet flushing, where rainwater was preferred (Table 3). Compared to rainwater and recycled wastewater, a smaller percentage of respondents viewed it as potentially harmful to human health, and a higher percentage viewed it as clean. Rainwater was perceived as the most environmentally friendly source (Table 4).

Israel: Overall, desalinated water was the preferred source of water for Israelis, for all purposes except watering plants and toilet flushing - where recycled water was the preferred choice (Table 3 ). In comparison to other locations, Israelis preferred the use of recycled water for cleaning the most, but the least for drinking (which they viewed as the most risky to human health). In comparison to other locations, Israelis preferred desalinated water most for washing clothes, cleaning and watering plants, and they were the location that had the highest percentage of respondents view desalinated water 'environmentally friendly' (Table 4).

Japan: For Japanese respondents, the preferred source of water varied across the purposes of use (Table 3). In comparison to other locations, they were least willing to use recycled water for cleaning, and they were least willing to use desalinated water for cooking, washing body and watering plants. A very low percentage of Japanese respondents perceived these water sources to be clean or convenient to use. Additionally in comparison to other locations, they were least willing to use rainwater for the four most close to person uses, which could be attributed to the Fukushima nuclear incident which occurred in March 2011. They had the lowest stated knowledge levels of all five water sources.

Jordan: For Jordanians, rainwater was the preferred water source for all uses except drinking and cooking, where desalinated water was the preferred source (Table 3). In comparison to other locations, they were the least willing to use rainwater for toilet flushing and watering plants. As seen in Table 4, Jordanians perceived rainwater to be the cleanest water source, and least harmful to people's health. Additionally, in comparison to other locations, Jordanians were most willing to use recycled water for drinking purposes. They were the location least willing to use desalinated water for washing clothes, cleaning and toilet flushing, but were the most willing to use it for cooking. In comparison to other locations, they had the highest knowledge levels for all water sources except for current tap water. The overall pattern of willingness to use the three water sources across the seven 
water use purposes which was observed for Jordan, appears to indicate a frugal attitude to water use, reflective of their stressed water context (see Table 1). The pattern of increasing acceptance of recycled water use observed for the whole sample holds for Jordan, but it does not hold for desalinated water and rainwater. Overall, willingness to use each alternative source decreases for low human-contact uses. In comparison to other locations their current tap water is viewed by the lowest percentage of respondents as clean, and convenient, and the perception that it is potentially harmful to human health is the highest of all locations. Further exploration of Jordanian attitudes to water in this respect would be insightful, particularly in a qualitative nature.

Mexico: For the Mexican respondents surveyed, rainwater was the preferred source for all uses except for drinking and cooking - where desalinated water was the preferred choice, in addition to washing body where it was equal with rainwater (Table 3). In comparison to other locations, they were the most willing to use desalinated water for drinking purposes, and body washing, and were the most willing to use rainwater for cleaning. As detailed in Table 4, they were the location who had the highest proportion of respondents perceive desalinated water to be convenient, and the second lowest percentage view their current tap water as convenient behind Jordan. They had the lowest percentage of respondents view each water source as environmentally friendly.

Norway: Norwegians preferred the use of rainwater for all uses except for drinking and cooking, for which desalinated water was the preferred use. In comparison to other locations, Norwegians were most willing to use recycled water for cooking, washing their bodies and washing their clothes, despite being the least water stressed location in the study (Table 1). This may be due to their high score in terms of environmental approach (Table 1). In comparison to the other locations, they were most willing to use rainwater for washing clothes. They were the location with the most positive perceptions of their current water supply (Table 4), with a high percentage of respondents viewing it as clean, and environmentally friendly, and the lowest percentage viewing it as potentially harmful to human health, and expensive.

$L A$ (USA): For the LA sample, desalinated water was the preferred water source for all uses except for watering plants - where rainwater was preferred, and toilet flushing - where recycled water was preferred. This may be due to the fact that desalinated water was perceived by the LA sample to be the second safest source of water (human health) behind bottled water. In comparison to other locations, they were most willing to use recycled water for toilet flushing, but least willing to use it for washing their body.

\section{Conclusions}

There is an increasing acknowledgement that traditional centralised water supply systems need to adapt to existing and future challenges, including climate change. One approach to this challenge is to diversify the water supply sources to include the use of alternative, non-traditional sources such as desalinated seawater, recycled wastewater and the more widespread use of rainwater tanks in developed nations. Yet, there is no guarantee that these changes will be accepted by the public involved. Thus, further research is needed to understand public opinion regarding these alternative water sources. The study reported in this paper addresses this research need.

Across the total sample of 1800 participants, the study found the ordered preference for recycled water and desalinated water across a range of water use purposes to be consistent with previous studies (Dolnicar and Hurlimann 2010; Dolnicar and Schäfer 2009). Desalinated water was preferred for all uses except the two least personal uses (garden watering and toilet flushing). Importantly, the study included a comparison with rainwater and found that rainwater was the preferred water source (in comparison to recycled water and desalinated water) for the least personal applications of water 
use: cleaning, toilet flushing and garden watering. For all other uses rainwater was the second preferred source behind desalinated water.

The results indicate that survey respondents differentiated between the various water sources and their applied use. Desalinated water, a purified and scientifically treated source (as defined in Box 1) was preferred over rainwater for close to person uses. But rainwater was preferred to recycled water that was "purified and scientifically tested" - despite the increased risk of possible ill health for its untreated rainwater consumption. It is possible that participants considered the option of a point of consumption treatment intervention such as boiling water which is common practice in many locations across the globe (Rosa and Clasen 2010). Further research to explore the reasons behind these preferences would be of interest, particularly in light of Hurliman and Dolnicar's (2010) research in Toowoomba Australia which indicated some residents were of the view that if recycled water was provided they would simply substitute another source for drinking.

The study offers insights into differences in stated willingness to use alternative water sources, and differences in water source perceptions, across nine locations. Importantly, significant differences emerged for preferred water source for all but three of the water source / purpose for use combinations researched. While the percentage of respondents willing to use each water source for each purpose varied between nations, what was consistent across most locations was is a higher willingness to use an alternative water sources for less personal uses of water. The exception is Jordan, where the aggregated results show a more nuanced approach to considering the use of alternative water sources, which we explain as reflective of their precarious water situation, and exposure to a more diverse array of water sources.

Our research into perceptions of five water sources across the nine locations, found that there were differences in the percentage of respondents who agreed with each perception statement for most water sources between locations. However, consistent across locations was the perception that bottled water is the cleanest of the water sources investigated. Also consistent was the order of perceived expensive water source: bottled water, followed by desalinated water, recycled wastewater, current water supply, then rainwater from a tank. Importantly, our study found that knowledge about recycled water and desalinated water was low across all locations in the study, and suggests the value of greater engagement with the community about these water sources. The results suggest that effective communication with the public regarding potential public harm, will aid an increase in willingness to use alternative water sources - given the negative correlation found between such perceptions and willingness to use each alternative water source.

We anticipate that there will be regional variations in attitudes to alternative water sources within the countries/locations sampled. This is anticipated due to the fact that water context varies greatly within some of the locations included in this study. We expect that this is the case for our sample of LA - that results for the general population of the USA would be very different given LA's specific water and cultural context.

The research results reported in this paper provide insights which may be of value to water supply policy makers, and specifically those companies working in diverse locations, and across national boundaries. The results of this study show that attitudes and perceptions of alternative water sources vary across the locations studied. Importantly for water policy makers, and multinational water companies, results indicate that investing in social research with the communities at the heart of water supply problems and decisions will be important - it can not be assumed that results of a study done in one location, will hold in another location. The results of the attitude and perception statements found in Table 5, can serve as a starting point for water communication strategies.

There are three key limitations to this study: first, the sample size of 200 study participants per location is relatively modest. As a consequence the population percentages presented, as is the case 
for any such study, may lie slightly above or below the real percentages, by the margin of error $(+/-$ $7 \%$ ). Secondly, while every effort was made for samples to be representative, it has to be acknowledged that this study was conducted in a range of very diverse locations which have different census statistics with different level of reliability. Some error may have resulted from such differences. More extensive research in each location would be beneficial. Finally, this study uses stated behaviours and stated behavioural intentions. They are not always the same as actual behaviour. Actual behaviour, however, is impossible to measure when such a large number of locations is compared and not all alternative water sources are available in all locations. Nevertheless, this represents a key limitation which needs to be taken into consideration when interpreting the findings.

\section{Acknowledgements}

This research was funded by the Australian Research Council under grants DP0878338 and DP110101347 (salary funding). Research assistance contributing to this paper was provided by Mathew Caulkins, Hannah Kelly and Yogita Rijal. Thanks to Lindsay Tanner, librarian with Oxford Brookes University for assistance finding sources for data in Table 1 while Anna Hurlimann was a visiting scholar at Oxford Brookes University on sabbatical in 2013.

\section{References}

Abdulla, F. A., and Al-Shareel, A. W. (2009). "Roof rainwater harvesting systems for household water supply in Jordan." Desalination, 243(1--3), 195-207.

Aitken, V., Bell, S., Hills, S., and Rees, L. (2014). "Public acceptability of indirect potable water reuse in the south-east of England." Water Science \& Technology: Water Supply, 14(5), 875-885.

Al-Mashaqbeh, O. A., Ghrair, A. M., and Megdal, S. B. (2012). "Grey Water Reuse for Agricultural Purposes in the Jordan Valley: Household Survey Results in Deir Alla." Water, 4(3), 580-596.

Alhumoud, J. M., and Madzikanda, D. (2010). "Public Perceptions On Water Reuse Options: The Case Of Sulaibiya Wastewater Treatment Plant In Kuwait." The International Business \& Economics Research Journal, 9(1), 141-158.

Barthwal, S., Chandola-Barthwal, S., Goyal, H., Nirmani, B., and Awasthi, B. (2014). "Socio-economic acceptance of rooftop rainwater harvesting - A case study." Urban Water Journal, 11(3), 231-239.

Biswas, A. K. (2008). "Integrated Water Resources Management: Is It Working?" International Journal of Water Resources Development, 24(1), 5-22.

Browning-Aiken, A., Ormerod, K. J., and Scott, C. A. (2011). "Testing the Climate for Non-Potable Water Reuse: Opportunities and Challenges in Water-Scarce Urban Growth Corridors." Journal of Environmental Policy \& Planning, 13(3), 253-275.

Bruvold, W. H. (1968). "Scales for Rating the Taste of Water." Journal of Applied Psychology, 52(3), 245-253.

Bruvold, W. H. (1972). Public Attitudes Toward Reuse of Reclaimed Water. University of California, Water Resources Centre, California.

Bruvold, W. H. (1988). "Public opinion on water reuse options." Journal of the Water Pollution Control Federation, 60(1), 45-49.

Bruvold, W. H. (1992). "Public Evaluation of Municipal Water Reuse Alternatives." Water Science and Technology, 26(7-8), 15371543.

Bruvold, W. H., and Ward, P. C. (1970). "Public attitudes toward uses of reclaimed wastewater." Water and Sewage Works, 117, 120122.

Carr, G., Potter, R. B., and Nortcliff, S. (2011). "Water reuse for irrigation in Jordan: Perceptions of water quality among farmers." Agricultural Water Management, 98(5), 847-854.

Cochran, W. G. (1977). Sampling techniques (3rd ed.).New York: John Wiley \& Sons

Davies, A. (2006). "Desalination plant dumped: it was a stinker with voters, to be frank"Sydney Morning Herald. City: Sydney.

Dobrowksy, P., Mannel, D., De Kwaadsteniet, M., Prozesky, H., Khan, W., and Cloete, T. (2014). "Quality assessment and primary uses of harvested rainwater in Kleinmond, South Africa." Water SA, 40(3), 401-406. 
Dolnicar, S., and Hurlimann, A. (2010). "Desalinated Versus Recycled Water - What Does the Public Think?", in I. C. Escobar and A. Schäfer, (eds.), Sustainable Water for the Future: Water Recycling Versus Desalination. Amsterdam: Elsevier B.V., pp. 375-388.

Dolnicar, S., Hurlimann, A., and Grün, B. (2014). "Branding water." Water Research, 57, 325-338.

Dolnicar, S., and Schäfer, A. I. (2009). "Desalinated versus recycled water: Public perceptions and profiles of the accepters." Journal of Environmental Management, 90(2), 888-900.

Domènech, L., and Saurí, D. (2011). "A comparative appraisal of the use of rainwater harvesting in single and multi-family buildings of the Metropolitan Area of Barcelona (Spain): social experience, drinking water savings and economic costs." Journal of Cleaner Production, 19, 598-608.

Doria, M. d. (2010). "Factors influencing public perception of drinking water quality." Water Policy, 12(1), 1-19.

du Pisani, P. L. (2005). "Direct Reclamation of Potable Water at Windhoek's Goreangab Reclamation Plant", in S. J. Khan, M. H. Muston, and A. I. Schaefer, (eds.), Proceedings from Integrated Concepts in Water Recycling. Wollongong: Wollongong University, pp. 193-202.

Fielding, K., Gardner, J., Leviston, Z., and Price, J. (2015). "Comparing Public Perceptions of Alternative Water Sources for Potable Use: The Case of Rainwater, Stormwater, Desalinated Water, and Recycled Water." Water Resources Management, 29(12), 45014518 .

Fielding, K. S., and Roiko, A. H. (2014). "Providing information promotes greater public support for potable recycled water." Water Research, 61(0), 86-96.

Food and Agriculture Organisation of the United Nations. (2013). "Aquastat (online data base)"Countries, regions, transboundary river basins. City: Food and Agricultural Organisation of the United Nations. Viewed on line 12/6/13 at: http://www.fao.org/nr/water/aquastat/countries_regions/index.stm.

Freedom House. (2011). Freedom in the World 2011: The Authoritarian Challenge to Democracy Washington: Freedom House. Viewed 14 November 2011 at: http://freedomhouse.org.

Gabe, J., Trowsdale, S., and Mistry, D. (2012). "Mandatory urban rainwater harvesting: learning from experience." Water Science \& Technology, 65(7), 1200-1207.

Gibson, F. L., Tapsuwan, S., Walker, I., and Randrema, E. (2015). "Drivers of an urban community's acceptance of a large desalination scheme for drinking water." Journal of Hydrology, 528, 38-44.

Haddad, B. M., Rozin, P., Nemeroff, C., and Slovic, P. (2009). The Psychology of Water Reclamation and Reuse: Survey Findings and Research Road Map, Alexandria: WateReuse Foundation.

Heyworth, J. S., Maynard, E. J., and Cunliffe, D. (1998). "Who Drinks What? Potable Water Use in South Australia." Water, Journal of the Australian Water Association, 25(1), 9-13.

Hrudey, S. E., and Hrudey, E. J. (2006). Safe Drinking Water: Lessons from Recent Outbreaks in Affluent Nations, London: IWA Publishing.

Hurd, R. (1993). Consumer Attitude Survey on Water Quality Issues: AWWA Research Foundation.

Hurlimann, A. (2008). Community Attitudes to Recycled Water Use and Urban Australian Case Study - Part 2, Adelaide: Cooperative Research Centre for Water Quality and Treatment

Hurlimann, A. (2011). "Household use of and satisfaction with alternative water sources in Victoria Australia." Journal of Environmental Management, 92, 2691-2697.

Hurlimann, A., and Dolnicar, S. (2010). "When Public Opposition Defeats Alternative Water Projects - the Case of Toowoomba Australia." Water Research, 44(1), 287-297.

Hurlimann, A., and McKay, J. (2007). "Urban Australians using recycled water for domestic non-potable use-An evaluation of the attributes price, saltiness, colour and odour using conjoint analysis " Journal of Environmental Management, 83(1), 93-104

Jeffrey, P., and Jefferson, B. (2003). "Public receptivity regarding "in-house" water recycling: results from a UK survey." Water Science and Technology: Water Supply, 3(3), 109-116.

Katuwal, H., and Bohara, A. K. (2011). "Coping with poor water supplies: empirical evidence from Kathmandu, Nepal." Journal of Water and Health, 9(1), 143-158.

Leonard, R., Mankad, A., and Alexander, K. (2015). "Predicting support and likelihood of protest in relation to the use of treated stormwater with managed aquifer recharge for potable and non-potable purposes." Journal of Cleaner Production, 92(0), 248-256.

Leong, C. (2015). "A quantitative investigation of narratives: recycled drinking water." Water Policy, 17(5), 831-847.

Macpherson, L., and Snyder, S. (2013). Downstream: Context, Understanding, Acceptance: Effect of Prior Knowledge of Unplanned Potable Reuse on the Acceptance of Planned Potable Reuse, Alexandria: WateReuse Research Foundation.

Marks, J. (2004). "Advancing Community Acceptance of Reclaimed Water." Water Journal of the Australian Water Association, $31(5), 46-51$. 
Marks, J. S., Martin, B., and Zadoroznyj, M. (2006). "Acceptance of Water Recycling In Australia: National Baseline Data." Water Journal of the Australian Water Association, 33(2), 151-157.

McKay, J., and Hurlimann, A. C. (2003). "Attitudes to Reclaimed Water for Domestic Use: Part 1 Age." Water, Journal of the Australian Water Association, 30(5), 45-49.

Mumford, L. (1989). The City in History, New York: MJF Books.

Nancarrow, B., Leviston, Z., Tucker, D., Greenhill, M., Price, J., and Dzidic, P. (2007). Community Acceptability of the Indirect Potable Use of Purified Recycled Water in South East Queensland and Preferences for Alternative Water Sources: A Baseline Measeure. CSIRO Perth.

OECD. (2008). OECD Environmental Data Compendium 2006-2008: Inland Waters. OECD.

Ormerod, K. J., and Scott, C. A. (2013). "Drinking Wastewater: Public Trust in Potable Reuse." Science, Technology \& Human Values, 38(3), 351-373.

Özdemir, S., Elliott, M., Brown, J., Nam, P. K., Hien, V. T., and Sobsey, M. D. (2011). "Rainwater harvesting practices and attitudes in the Mekong Delta of Vietnam." Journal of Water, Sanitation and Hygiene for Development, 1(3).

Parag, Y., and Roberts, J. T. (2009). "A Battle Against the Bottles: Building, Claiming, and Regaining Tap-Water Trustworthiness." Society \& Natural Resources, 22(7), 625-636.

Paulhus, D. L. (1991). "Measurement and control of response bias", in J. P. Robinson, P. R. Shaver, and L. S. Wrightsman, (eds.), Measures of Personality and Social Psychological Attitudes. San Diego: Academic Press, pp. 17-59.

Price, J., Fielding, K., Leviston, Z., Bishop, B., Nicol, S., Greenhill, M., and Tucker, D. (2010). Community Acceptability of the Indirect Potable Use of Purified Recycled Water in South-East Queensland: Final Report of Monitoring Surveys. Urban Water Security Research Alliance, Brisbane.

Resource Trends Inc. (2004). Best Practices for Developing Indirect Potable Reuse Projects: Phase 1, Alexandria: WateReuse Association.

Rosa, G., and Clasen, T. (2010). "Estimating the scope of household water treatment in low- and medium-income countries." The American Journal Of Tropical Medicine And Hygiene, 82(2), 289-300.

Roseth, N. (2008). Community views on recycled water: the impact of information. Cooperative Research Centre for Water Quality and Treatment, Adelaide.

Rossiter, J. R., Dolnicar, S., and Grün, B. (2015). "Why level-free forced choice binary measures of brand benefit beliefs work well." International Journal of Market Research, 57(2), 1-9.

Sodha, S. V., Menon, M., Trivedi, K., Ati, A., Figueroa, M. E., Ainslie, R., Wannemuehler, K., and Quick, R. (2011). "Microbiologic effectiveness of boiling and safe water storage in south Sulawesi, Indonesia." Journal of Water and Health, 9(3), 577-585.

Sydney Water. (1996). Community Views on Water Reuse. Research Report, Sydney Water, Sydney.

The World Bank. (2012). 2012 World Development Indicators. The World Bank, Washington.

Theodori, G., Avalos, M., Burnett, D. B., and Veil, J. A. (2011). "Public perception of desalinated produced water from oil and gas field operations: a replication." Journal of Rural Social Sciences, 26(1), 92-106.

Water Corporation. (2015). "Water Sources". Viewed 15 December at: http://www.watercorporation.com.au/water-supply-andservices/rainfall-and-dams/sources

World Water Assessment Programme (United Nations). (2009). Water in a changing world / World Water Assessment Programme: Paris: UNESCO Publishing; London: Earthscan, c2009. [3rd ed.].

Yale Center for Environmental Law and Policy, Yale University Center for International Earth Science Information Network, Columbia University, World Economic Forum, Joint Research Centre, and European Commission. (2005). 2005 Environmental Sustainability Index, Palisades, NY: NASA Socioeconomic Data and Applications Center. Viewed 14 November 2011 at: http://sedac.ciesin.columbia.edu/data/set/esi-environmental-sustainability-index-2005. 


\section{Box 1: Information about water sources provided to survey participants}

Throughout the survey:

- We will use the term "rainwater" to describe "rainwater from a rainwater collection tank on your property" (rainwater collected from the roof of your house)

- We will use the term "bottled water" to describe "water sold in bottles by food companies that is widely available to the public for purchase and consumption"

- We will use the term "your current tap water supply" to describe the "water you presently use throughout your dwelling (home)"

- We will use the term "recycled water" to describe "highly purified wastewater deemed by scientists as safe for human consumption". Such water is currently used for drinking purposes in countries including the USA, Singapore and Namibia.

- We will use the term "desalinated water" to describe "highly purified seawater deemed by scientists and public health officials as safe for human consumption." Such water is currently used for drinking purposes in countries including the USA, Australia and the Middle East.

And we will assume that both recycled and desalinated water were treated to the same level of water quality. 
Figure 1: Intended use of recycled, desalinated and rainwater for various uses - whole sample

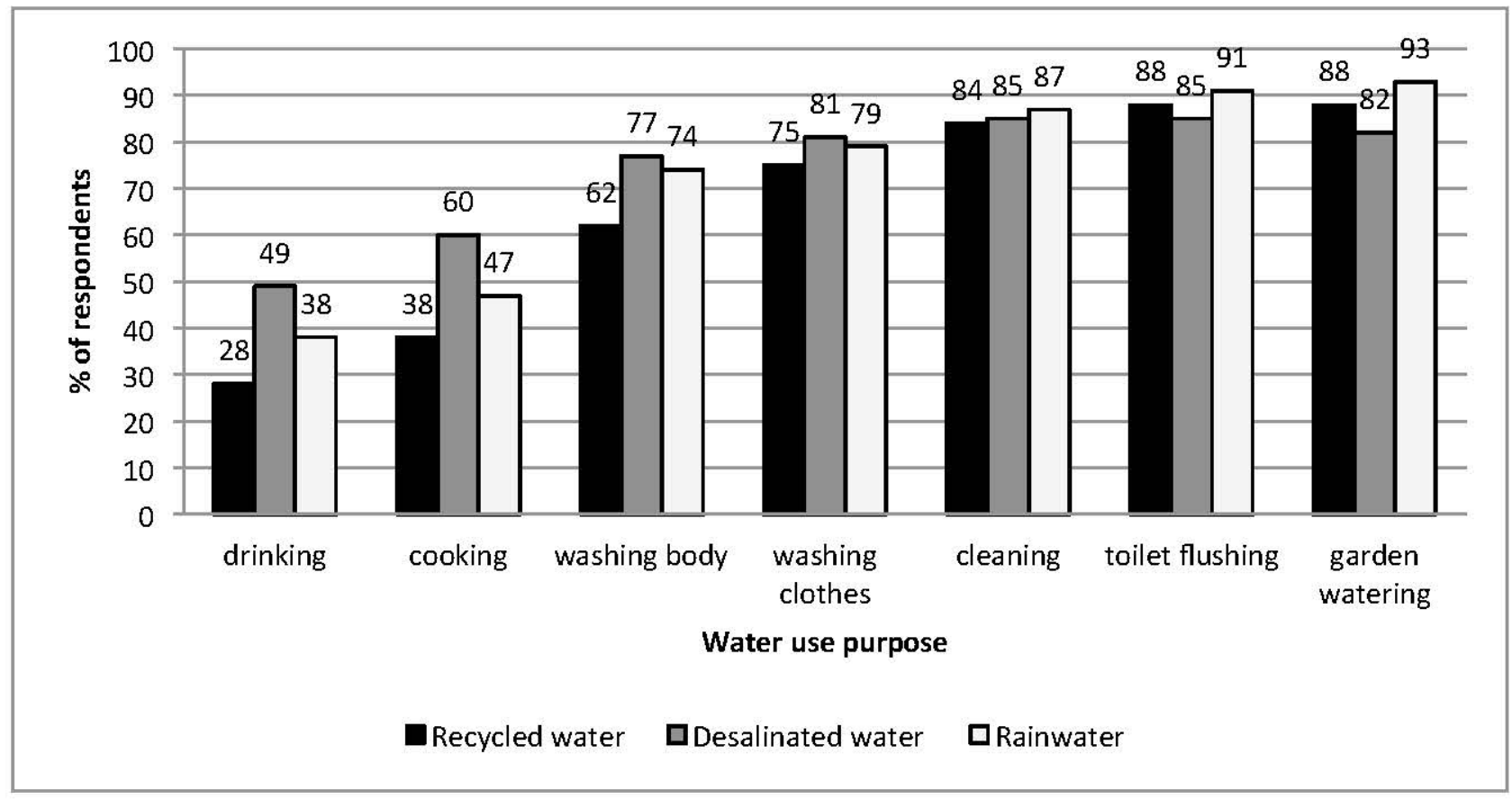


Table 1: Description of sample country characteristics

\begin{tabular}{|c|c|c|c|c|c|c|c|c|c|c|c|c|}
\hline Country & $\frac{\lambda}{\sum_{\bar{Z}}^{2}}$ & 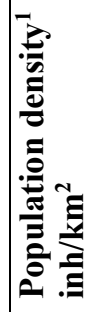 & 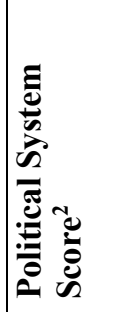 & 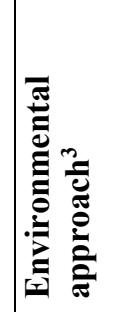 & 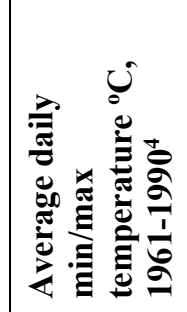 & 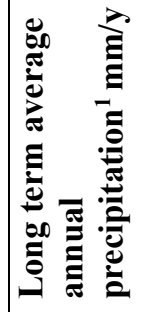 & | & 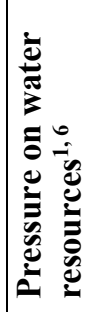 & 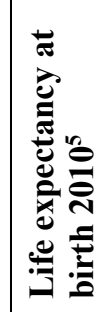 & 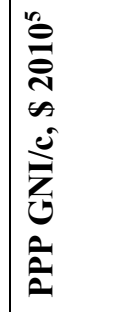 & 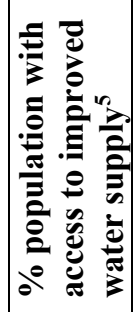 & 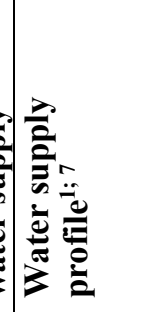 \\
\hline Australia & $\begin{array}{l}\text { Many capital cities are facing challenges to water supply. Significant drought period } \\
\text { experienced in the } 2000 \text { s in many regions of the country. Augmentation of supply with } \\
\text { multiple sources is being implemented / considered in numerous locations (Grant et al. } \\
\text { 2013). }\end{array}$ & 3 & 'free' & 17 & $14.9 / 28.4$ & 534 & 1152 & 4 & 82 & 36,910 & 100 & $\begin{array}{l}S=73 \% \\
G=25 \% \\
R=2 \% \\
D=<1 \%\end{array}$ \\
\hline Belgium & $\begin{array}{l}\text { Potable reuse occurs through aquifer recharge e.g in Torreele (Water Supply and Sanitation } \\
\text { Technology Platform 2010) }\end{array}$ & 352 & 'free' & 20 & $5.5 / 13.6$ & 847 & 589 & 34 & 80 & 38,240 & 100 & $\begin{array}{l}\mathrm{S}=90 \% \\
\mathrm{G}=10 \% \\
\mathrm{R}=<1 \%\end{array}$ \\
\hline Canada & $\begin{array}{l}\text { Historically Canada has had a plentiful supply of fresh water and high per capita use. There } \\
\text { is growing awareness of the need for sustainable water management due to increasing water } \\
\text { use, population, and pollution (Environment Canada 2011; Fennell and Kielbasinski 2014). }\end{array}$ & 3 & 'free' & 16 & $-10.1 /-0.6$ & 537 & 1589 & 1 & 81 & 38,370 & 100 & $\begin{array}{l}\mathrm{S}=96 \% \\
\mathrm{G}=4 \% \\
\mathrm{D}=<1 \%\end{array}$ \\
\hline Israel & $\begin{array}{l}\text { Israel has a low per capita freshwater availability, and has introduced a diverse range of } \\
\text { projects to address this water scarcity, including being an early adopter of water recycling } \\
\text { for agricultural reuse, and more recently desalination of seawater for potable use (Alon } \\
2006) \text {. }\end{array}$ & 342 & 'free' & 30 & $13.4 / 25.0$ & 435 & 282 & 79 & 82 & 27,660 & 100 & $\begin{array}{l}\mathrm{R}=13 \% \\
\mathrm{D}=7 \% \\
\mathrm{~S} \& \mathrm{G}=80 \\
\%\end{array}$ \\
\hline Japan & $\begin{array}{l}\text { Non-potable reuse occurs (Kimura et al. 2007; Yamagata et al. 2002). Water shortages } \\
\text { frequently experienced in many parts of the country, with reduced water pressure and hours } \\
\text { of supply a measure during these periods (Morimasa et al.2014). }\end{array}$ & 335 & 'free' & 5 & $7.0 / 15.3$ & 1668 & 714 & 21 & 83 & 34,610 & 100 & $\begin{array}{l}\mathrm{S}=82 \% \\
\mathrm{G}=18 \% \\
\mathrm{D}=<1 \% \\
\mathrm{R}=<1 \%\end{array}$ \\
\hline \begin{tabular}{|l|} 
Jordan \\
\end{tabular} & $\begin{array}{l}\text { Arid - Semi-Arid country. High water stress in terms of availability of water per capita, and } \\
\text { population growth. Unreliable water supply based on rotation and prone to failure. } \\
\text { Alternative water sources sought by individuals including rainwater. (Abdulla and Al- } \\
\text { Shareel 2009). }\end{array}$ & 71 & $\begin{array}{l}\text { 'not } \\
\text { free' }\end{array}$ & 52 & $11.2 / 25.4$ & 111 & 166 & 99 & 73 & 5,800 & 97 & $\begin{array}{l}R=9 \% \\
D=1 \% \\
S=31 \% \\
G=59 \%\end{array}$ \\
\hline Mexico & $\begin{array}{l}\text { Mexico faces a challenging water future (Spring 2011). Mexico City's water supply is } \\
\text { significantly stressed, where extraction of water exceeds natural availability, yet water } \\
\text { consumption is amongst the highest in the nation (Novelo and Tapia 2011). }\end{array}$ & 58 & $\begin{array}{l}\text { "partly } \\
\text { free' }\end{array}$ & 59 & $13.5 / 28.5$ & 752 & 700 & 17 & 77 & 14,340 & 96 & $\begin{array}{l}R=2.5 \% \\
S=60 \% \\
G=37.5 \%\end{array}$ \\
\hline Norway & $\begin{array}{l}\text { Norway has a plentiful supply of freshwater. Hydroelectric power generation and flooding } \\
\text { are key future concerns (Lawrence and Haddeland 2011; Norwegian Ministry of Petroleum } \\
\text { and Energy 2015). }\end{array}$ & 15 & 'free' & 3 & $-2.0 / 5.0$ & 1414 & 622 & 1 & 81 & 58,570 & 100 & $\begin{array}{l}\mathrm{S} \& \mathrm{G}=100 \\
\%\end{array}$ \\
\hline $\begin{array}{l}\text { United } \\
\text { States of } \\
\text { America }\end{array}$ & $\begin{array}{l}\text { Many areas of the USA are facing increasing water scarcity, water consumption per capita } \\
\text { is high, and potable reuse is being considered and implemented in numerous areas (National } \\
\text { Research Council 2012). Potable reuse occurs through aquifer recharge in parts of the } \\
\text { country including the Orange County in Los Angeles (Guendert 2004), hence focus of the } \\
\text { sample for the USA is on LA. }\end{array}$ & 32 & 'free' & 14 & $2.2 / 14.9$ & 715 & 1583 & 16 & 78 & 47,310 & 99 & $\begin{array}{l}S=77 \% \\
G=23 \% \\
R=<1 \% \\
D=<1 \%\end{array}$ \\
\hline
\end{tabular}

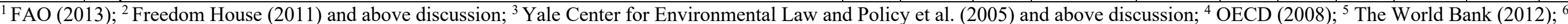

total water withdrawn as a percentage of annual renewable water resources (FAO 2013); ${ }^{7} \mathrm{R}=$ treated wastewater, $\mathrm{D}=$ desalinated water, $\mathrm{S}=$ surface water $\mathrm{G}=$ groundwater 
Table 2: Drinking water source - percentage of respondents who indicated they used each water source for drinking purposes in each location

\begin{tabular}{|c|c|c|c|c|c|c|c|c|c|}
\hline Country/Region & $\begin{array}{c}\text { Town } \\
\text { supplied } \\
\text { water \% }\end{array}$ & $\begin{array}{c}\text { Rainwater } \\
\text { from tank } \\
\%\end{array}$ & $\begin{array}{c}\text { Bottled } \\
\text { water } \%\end{array}$ & $\begin{array}{c}\text { Ground } \\
\text { water \% }\end{array}$ & $\begin{array}{c}\text { I boil } \\
\text { my } \\
\text { water } \\
\%\end{array}$ & $\begin{array}{c}\text { Recycled } \\
\text { water } \\
\%\end{array}$ & $\begin{array}{c}\text { Desalinated } \\
\text { water } \\
\%\end{array}$ & $\begin{array}{c}\text { Other } \\
\%\end{array}$ & $\begin{array}{c}\text { Don't } \\
\text { know \% }\end{array}$ \\
\hline Belgium & 55 & 5 & 64 & 3 & 1 & 2 & 0 & 3 & 0 \\
\hline Norway & 85 & 1 & 19 & 8 & 4 & 2 & 1 & 2 & 4 \\
\hline Israel & 56 & 1 & 47 & 3 & 8 & 0 & 3 & 15 & 2 \\
\hline Australia & 75 & 10 & 27 & 1 & 10 & 0 & 1 & 7 & 3 \\
\hline LA (USA) & 45 & 1 & 61 & 3 & 8 & 2 & 1 & 8 & 3 \\
\hline Canada & 68 & 1 & 45 & 8 & 8 & 3 & 1 & 8 & 2 \\
\hline Mexico & 56 & 13 & 37 & 23 & 4 & 7 & 4 & 3 & 4 \\
\hline Japan & 69 & 1 & 46 & 7 & 10 & 1 & 0 & 9 & 2 \\
\hline Jordan & 30 & 19 & 67 & 11 & 14 & 17 & 7 & 4 & 1 \\
\hline
\end{tabular}

$\square$ most stated water source; $\square$ second most stated source; $\square$ third most stated source 
Table 3: Intended use of recycled (R), desalinated (D), and rainwater from tank (T), in a water shortage scenario - a comparison across nine locations

\begin{tabular}{|c|c|c|c|c|c|c|c|c|c|c|c|c|c|c|c|c|c|c|c|c|c|}
\hline \multirow{2}{*}{\begin{tabular}{|l|} 
Water Use \\
$\begin{array}{l}\text { Water Type / } \\
\text { Location }\end{array}$ \\
\end{tabular}} & \multicolumn{3}{|c|}{$\begin{array}{c}\text { Watering plants } \\
\% \text { yes }\end{array}$} & \multicolumn{3}{|c|}{$\begin{array}{c}\text { Washing clothes } \\
\% \text { yes }\end{array}$} & \multicolumn{3}{|c|}{$\begin{array}{c}\text { Washing my body } \\
\% \text { yes }\end{array}$} & \multicolumn{3}{|c|}{$\begin{array}{c}\text { Drinking } \\
\% \text { yes }\end{array}$} & \multicolumn{3}{|c|}{$\begin{array}{c}\text { Toilet flushing } \\
\% \text { yes }\end{array}$} & \multicolumn{3}{|c|}{$\begin{array}{c}\text { Cooking } \\
\% \text { yes }\end{array}$} & \multicolumn{3}{|c|}{$\begin{array}{c}\text { Cleaning } \\
\% \text { yes }\end{array}$} \\
\hline & $\mathrm{R}^{*}$ & $\mathrm{D}^{*}$ & $\mathrm{~T}$ & $\mathrm{R}^{*}$ & $\mathrm{D}^{*}$ & $\mathrm{~T}^{*}$ & $\mathrm{R}^{*}$ & $\mathrm{D}$ & $\mathrm{T}^{*}$ & $\mathrm{R}^{*}$ & $\mathrm{D}^{*}$ & $\mathrm{~T}^{*}$ & $\mathrm{R}^{*}$ & $\mathrm{D}^{*}$ & $\mathrm{~T}^{*}$ & $\mathrm{R}^{*}$ & $\mathrm{D}^{*}$ & $\mathrm{~T}^{*}$ & $\mathrm{R}^{*}$ & $\mathrm{D}^{*}$ & $\mathrm{~T}$ \\
\hline Belgium & 86 & 81 & 96 & 79 & 81 & 80 & 67 & 74 & 63 & 28 & 34 & 16 & 86 & 84 & 96 & 41 & 53 & 24 & 86 & 85 & 92 \\
\hline Norway & 87 & 81 & 91 & 84 & 84 & 88 & 75 & 78 & 86 & 32 & 46 & 39 & 88 & 86 & 92 & 48 & 60 & 56 & 83 & 86 & 88 \\
\hline Israel & 95 & 94 & 94 & 76 & 88 & 82 & 59 & 81 & 76 & 13 & 52 & 45 & 92 & 90 & 91 & 31 & 65 & 53 & 88 & 92 & 87 \\
\hline Australia & 96 & 84 & 91 & 75 & 87 & 86 & 56 & 80 & 83 & 33 & 59 & 66 & 94 & 92 & 92 & 42 & 68 & 73 & 86 & 89 & 87 \\
\hline LA (USA) & 93 & 85 & 96 & 74 & 83 & 82 & 53 & 74 & 69 & 26 & 40 & 34 & 95 & 91 & 93 & 39 & 57 & 44 & 86 & 92 & 87 \\
\hline Canada & 89 & 80 & 95 & 73 & 75 & 80 & 58 & 74 & 70 & 25 & 48 & 26 & 90 & 83 & 91 & 35 & 58 & 44 & 83 & 84 & 83 \\
\hline Mexico & 86 & 79 & 95 & 79 & 82 & 86 & 67 & 82 & 82 & 32 & 62 & 43 & 88 & 83 & 95 & 42 & 67 & 51 & 86 & 84 & 95 \\
\hline Japan & 85 & 75 & 94 & 73 & 76 & 52 & 60 & 72 & 47 & 24 & 42 & 10 & 85 & 85 & 91 & 25 & 45 & 11 & 85 & 83 & 84 \\
\hline \begin{tabular}{|l|} 
Jordan \\
\end{tabular} & 77 & 80 & 87 & 61 & 74 & 81 & 60 & 79 & 88 & 37 & 59 & 61 & 73 & 67 & 79 & 40 & 70 & 67 & 68 & 76 & 83 \\
\hline Average & 88 & 82 & 93 & 75 & 81 & 79 & 62 & 77 & 74 & 28 & 49 & 38 & 88 & 85 & 91 & 38 & 60 & 47 & 84 & 85 & 87 \\
\hline
\end{tabular}

Uses and water types were significantly different between countries at the 0.01 level using chi-square tests as indicated with *

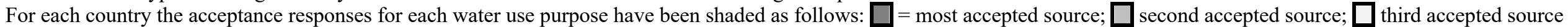


Table 4: Perceptions of recycled water (R), desalinated water (D), rainwater from tank (T), current water supply (C), and bottled water (B) - a comparison across nine locations

\begin{tabular}{|c|c|c|c|c|c|c|c|c|c|c|c|c|c|c|c|c|c|c|c|c|c|c|c|c|c|c|c|c|c|c|}
\hline \multirow{2}{*}{\begin{tabular}{|l}
$\begin{array}{l}\text { Perception } \\
\text { about water } \\
\text { source }\end{array}$ \\
$\begin{array}{l}\text { Water Type / } \\
\text { Location }\end{array}$ \\
\end{tabular}} & \multicolumn{5}{|c|}{$\begin{array}{l}\text { Is environmentally friendly } \\
(\% \text { yes })\end{array}$} & \multicolumn{5}{|c|}{$\begin{array}{l}\text { Is potentially harmful to } \\
\text { people's health ( } \% \text { yes) }\end{array}$} & \multicolumn{5}{|c|}{ Is expensive (\% yes) } & \multicolumn{5}{|c|}{ Is clean $(\%$ yes $)$} & \multicolumn{5}{|c|}{$\begin{array}{l}\text { I know a lot about this kind of } \\
\text { water }(\% \text { yes })\end{array}$} & \multicolumn{5}{|c|}{ Is convenient ( $\%$ yes $)$} \\
\hline & $\mathrm{R}^{*}$ & $\mathrm{D}^{*}$ & $\mathrm{~T}^{*}$ & $\mathrm{C}^{*}$ & $\mathrm{~B}^{*}$ & $\mathrm{R}^{*}$ & $\mathrm{D}^{*}$ & $\mathrm{~T}^{*}$ & $\mathrm{C}^{*}$ & $\mathrm{~B}^{*}$ & $\mathrm{R}^{*}$ & $\mathrm{D}^{*}$ & $\mathrm{~T}$ & $\mathrm{C}^{*}$ & $\mathrm{~B}^{*}$ & $\mathrm{R}^{*}$ & $\mathrm{D}^{*}$ & $\mathrm{~T}^{*}$ & $\mathrm{C}^{*}$ & $\mathrm{~B} * *$ & $\mathrm{R}^{*}$ & $\mathrm{D}^{*}$ & $\mathrm{~T}^{*}$ & $\mathrm{C}^{*}$ & $\mathrm{~B}^{*}$ & $\mathrm{R}^{*}$ & $\mathrm{D}^{*}$ & $\mathrm{~T}^{*}$ & $\mathrm{C}^{*}$ & $\mathrm{~B}^{*}$ \\
\hline Belgium & 79 & 77 & 85 & 81 & 63 & $\underline{42}$ & 29 & 52 & 18 & $\underline{8}$ & 58 & 60 & $\underline{4}$ & 56 & 81 & 66 & 70 & 30 & 84 & 96 & 11 & 12 & 43 & 48 & 54 & 67 & 58 & 85 & 93 & 88 \\
\hline Norway & 69 & 63 & 80 & 91 & 41 & 51 & 31 & 54 & $\underline{13}$ & 14 & 52 & 55 & 7 & $\underline{14}$ & 87 & 46 & 62 & 34 & 84 & $\underline{86}$ & 14 & 14 & 30 & 62 & 54 & 41 & 47 & 58 & 88 & 74 \\
\hline Israel & 79 & 82 & 94 & 82 & 44 & 66 & $\underline{28}$ & 24 & 33 & 21 & 50 & 68 & 8 & 45 & 91 & 36 & 72 & 68 & 61 & 88 & 10 & 18 & 37 & 56 & 53 & 41 & 54 & 51 & 94 & $\underline{66}$ \\
\hline Australia & 70 & 56 & 96 & 72 & $\underline{30}$ & 44 & 27 & 31 & 33 & 22 & 75 & 80 & 8 & $\underline{14}$ & 88 & 66 & 76 & 68 & 75 & 91 & 20 & 17 & 67 & 62 & 50 & 35 & 32 & 71 & 97 & 76 \\
\hline Canada & 76 & 70 & 85 & 67 & 44 & 52 & 34 & 55 & 32 & 24 & 56 & 68 & 10 & 16 & 77 & 57 & 68 & 38 & 79 & 90 & 15 & 11 & 47 & 72 & 65 & 38 & 38 & 62 & 92 & 84 \\
\hline Mexico & $\underline{35}$ & $\underline{28}$ & $\underline{21}$ & $\underline{29}$ & 32 & 53 & 32 & 36 & 54 & 10 & 53 & 66 & 9 & 36 & 81 & 55 & 66 & 47 & 51 & 96 & 18 & 15 & 54 & 54 & 68 & 58 & 61 & 69 & 66 & 89 \\
\hline Japan & 58 & 67 & $\overline{74}$ & 67 & 54 & 75 & 42 & 80 & 40 & 20 & $\underline{38}$ & 62 & 5 & 24 & 89 & 25 & $\underline{49}$ & $\underline{7}$ & 81 & 92 & $\underline{4}$ & $\underline{6}$ & $\underline{12}$ & $\underline{29}$ & $\underline{28}$ & $\underline{20}$ & $\underline{23}$ & $\underline{35}$ & 91 & 96 \\
\hline Jordan & 45 & 73 & 97 & 68 & 77 & 81 & 43 & 26 & 64 & 33 & 40 & 54 & 12 & 33 & 93 & 24 & $\overline{58}$ & 76 & 47 & 88 & 38 & 38 & 81 & 69 & 81 & 25 & 51 & 83 & 57 & 93 \\
\hline Average & 65 & 66 & 80 & 70 & 49 & 57 & 34 & 45 & 37 & 19 & 54 & 65 & 8 & 29 & 85 & 48 & 65 & 46 & 69 & 91 & 16 & 16 & 46 & 57 & 58 & 40 & 43 & 62 & 86 & 84 \\
\hline
\end{tabular}

Uses and water types were significantly different between countries at the 0.01 level using chi-square tests as indicated with *; at the 0.05 level with **

The country with the highest rate of agreement per water source for each perception statement is indicated in bold;

The country with the lowest rate of agreement per water source for each perception statement is indicated with underline.

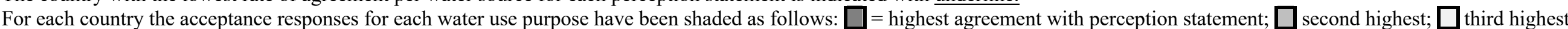

